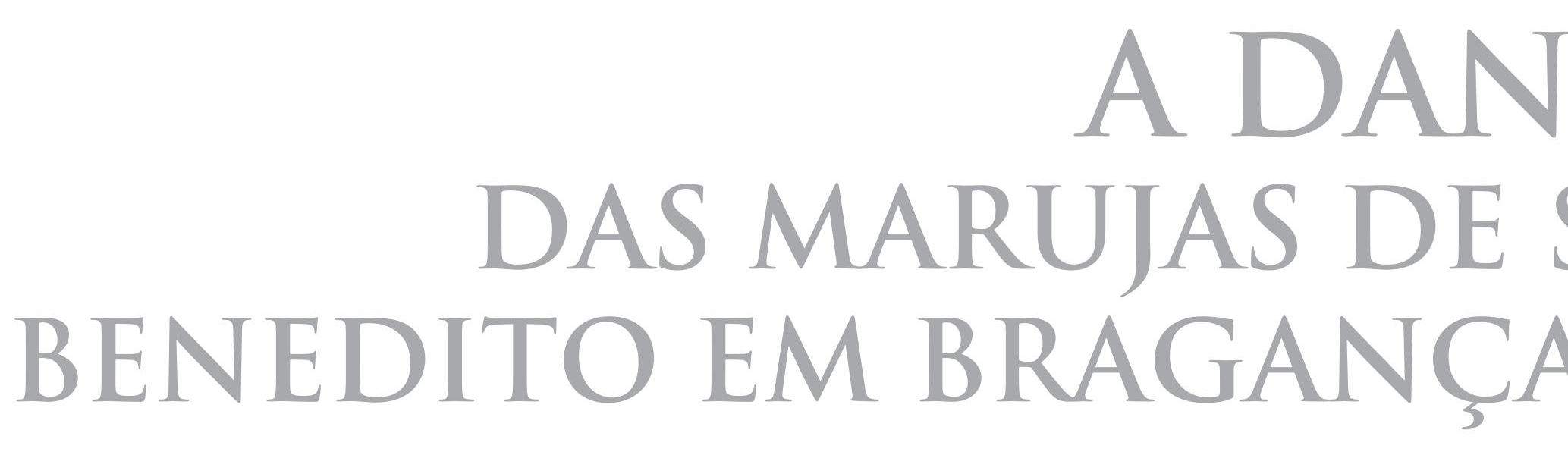




\section{A DANCCA DAS MARUJAS DE SÃO BENEDITO EM BRAGANÇA-PA}

ESTER PAIX ÃO CORRÊA

MESTRA EM ANTROPOLOGIA SOCIAL (PPGA/UFPA) 
No mês de dezembro, a cidade de Bragança-PA, é especialmente colorida pelo clima de festa e se prepara para os rituais que compreendem a Festividade de São Benedito, em especial para a Marujada, uma dança que ocorre dentro da festa. São 217 anos reunindo marujos e marujas, com seus trajes nas cores branco, azul e vermelho, assim como pelo colorido das fitas que enfeitam os chapéus das marujas bragantinas, dentre todos os rituais que compõem a festa é o que mais se destaca. $\mathrm{Na}$ dança as mulheres, chamadas de marujas, são as protagonistas, além de serem em maior quantidade. A Marujada é um ritual com características matriarcais, tem como representação máxima uma mulher, a Capitoa. Nessa participação majoritária, geralmente as mulheres estão presentes em todas as etapas da festa, da organização, no decorrer do ano, à execução da dança. Seus trajes são mais elaborados, e por tanto se destacam esteticamente; usam blusas de renda em modelo padrão na cor branca, saias longas rodadas nas cores azul ou vermelho e anáguas - a cor varia nos dias 25 e 26 de dezembro - e chapéus decorados com penas de pato e fitas coloridas. Esta indumentária é objeto de grande valor simbólico na dança, e é complementado pelo uso de acessórios como brincos, colares, pulseiras e maquiagem, pois é essencial que as marujas estejam bonitas. Soma-se a todos esses elementos a performance ritualística quando as mulheres saem as ruas com os pés descalços rememorando os pés no chão dos negros escravizados de um passado colonial doloroso. Suas principais característi- cas são a musicalidade, a dança, a religiosidade e a ornamentação estética. A dança acontece em diversos momentos da festividade e, por seu caráter de manifestação cultural, também fora do contexto sagrado também na forma de apresentação cultural em outras cidades, a até outros estados do Brasil. Este ensaio apresenta fotografias que ressaltam o protagonismo das marujas na Festividade de São Benedito capturadas durante a festa no mês de dezembro nos anos de 2015 e 2016, e é resultado da pesquisa de campo realizada durante a festividade como parte da pesquisa de Mestrado em Antropologia Social, PPGA/UFPA.

\section{Ester Paixão Corrêa} esterzinhacorrea@yahoo.com.br 


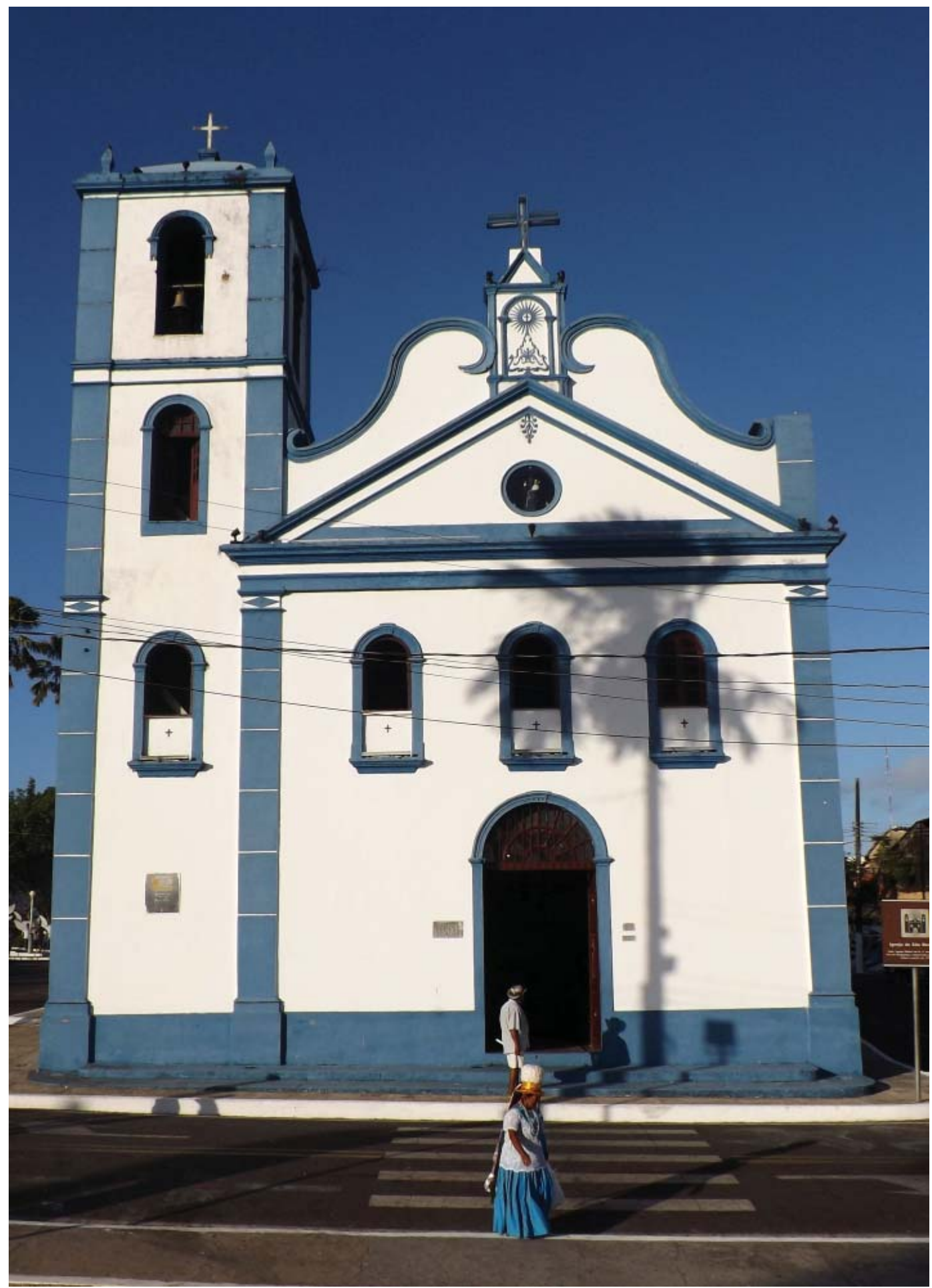

Figura 1 - A Igreja de São Benedito como pano de fundo de uma manifestação que inicia no dia 18 de dezembro, quando ocorre a Alvorada, que é a abertura da Festa de São Benedito, quando marujos e marujas se reúnem na Igreja às $5 \mathrm{~h}$ da manhã para louvar o santo. 


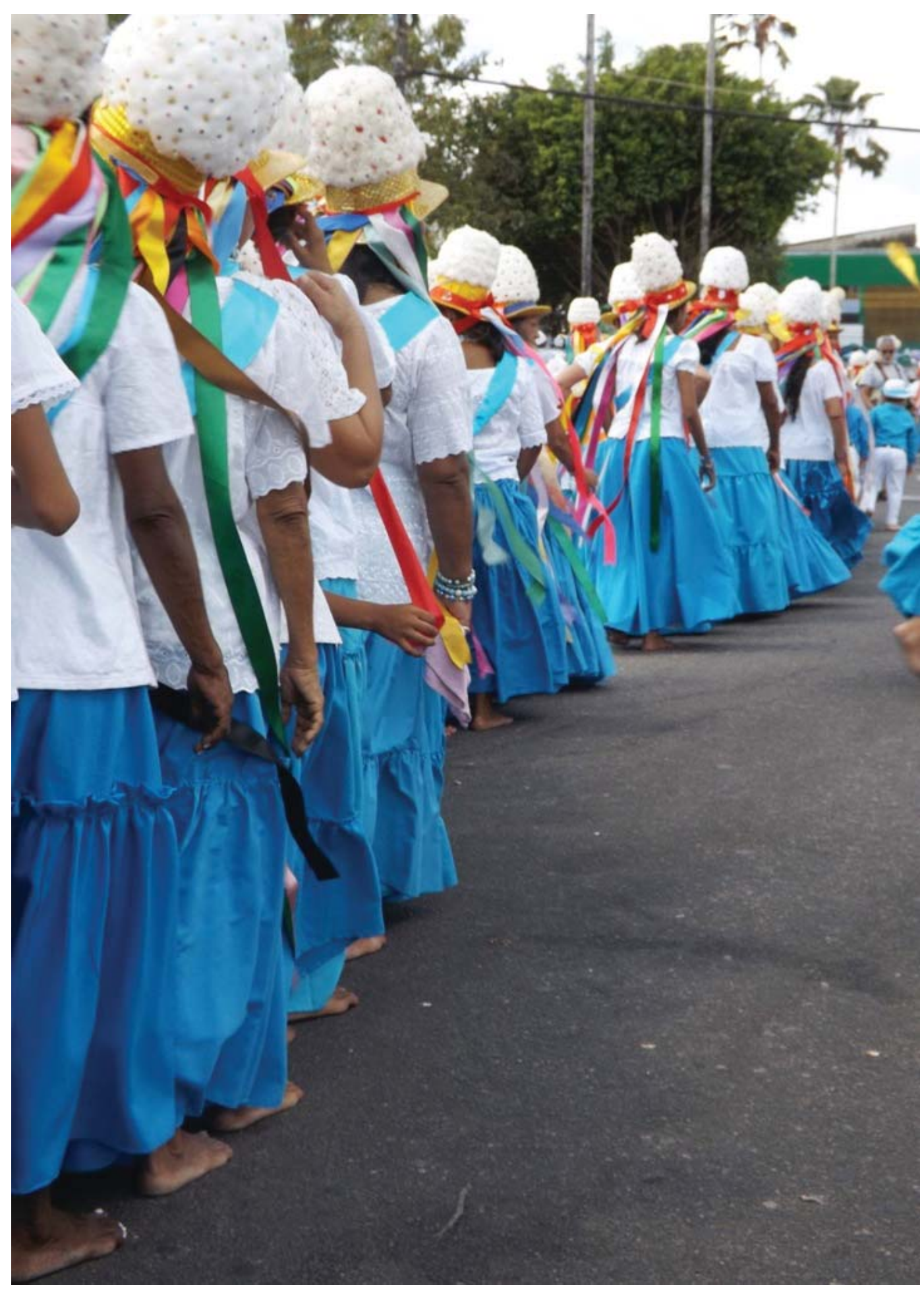

Figura 2 - Os pés descalços é uma das grandes características e também uma exigência para a participação na Festa como maruja. As filas são formadas sempre que necessário para deslocar-se de um espaço a outro, a composição da fila é hierarquizada; encabeçada pelas marujas permanentes da Irmandade e que participam diretamente da organização da Festa. 


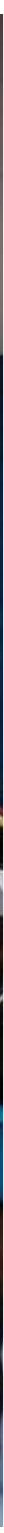

Figura 3 - No dia 25 de dezembro dentro do barracão da Marujada, dia do menino Jesus, as marujas se apresentam com os trajes azuis, é a primeira apresentação da dança na Festa. Muitas marujas dançam entre si, pois são em maior número no salão de apresentação. 
Corrêa, E. P.

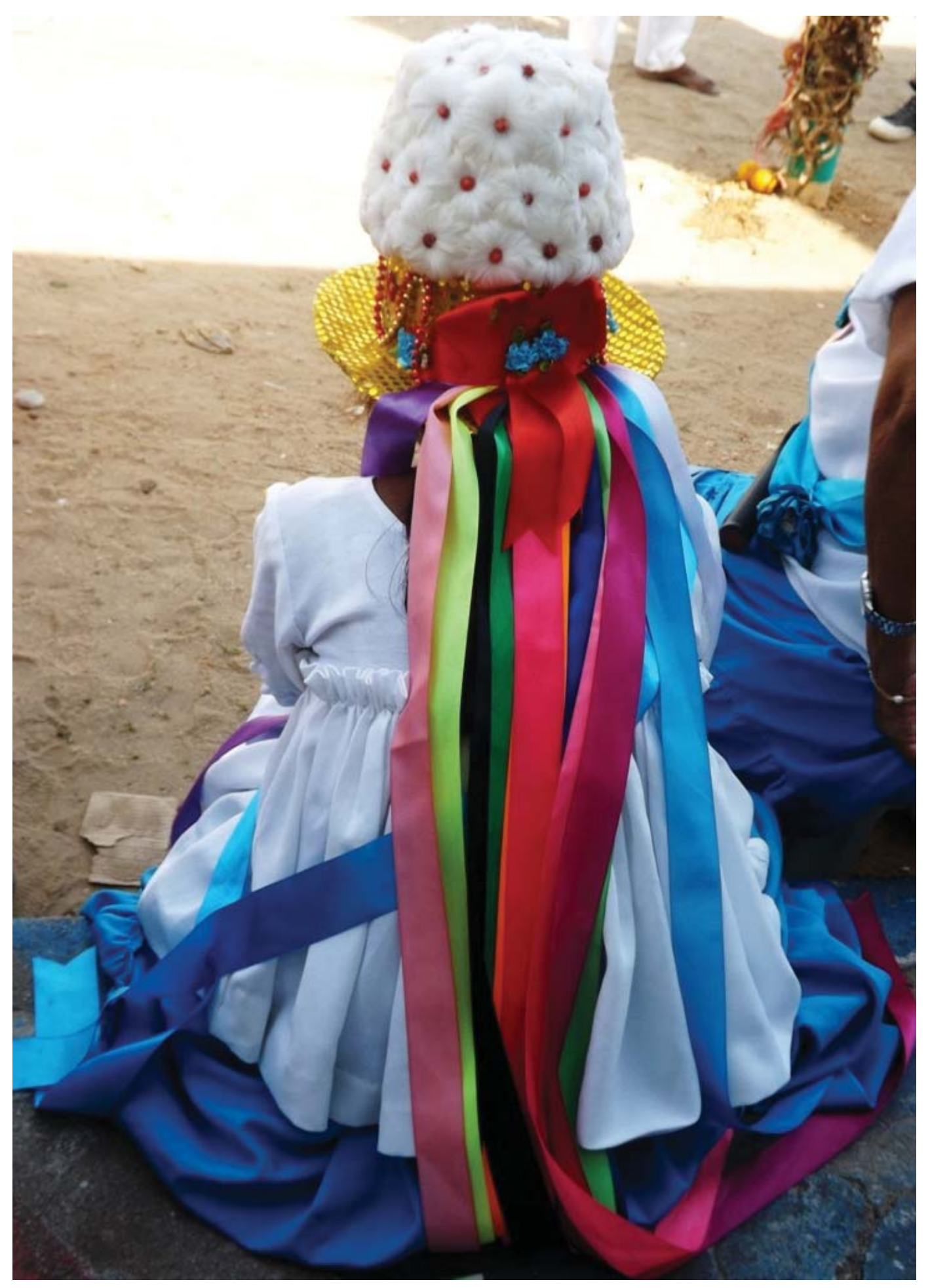

Figura 4 - O chapéu com fitas coloridas é um grande destaque da indumentária, possui 14 fitas coloridas que simbolizam os agentes que iniciaram a Marujada, dentre as quais a de cor preta referencia aos negros escravizados. E ornamentado com penas de pato na parte superior e muitos são confeccionados pelas próprias marujas que também são artesãs. 


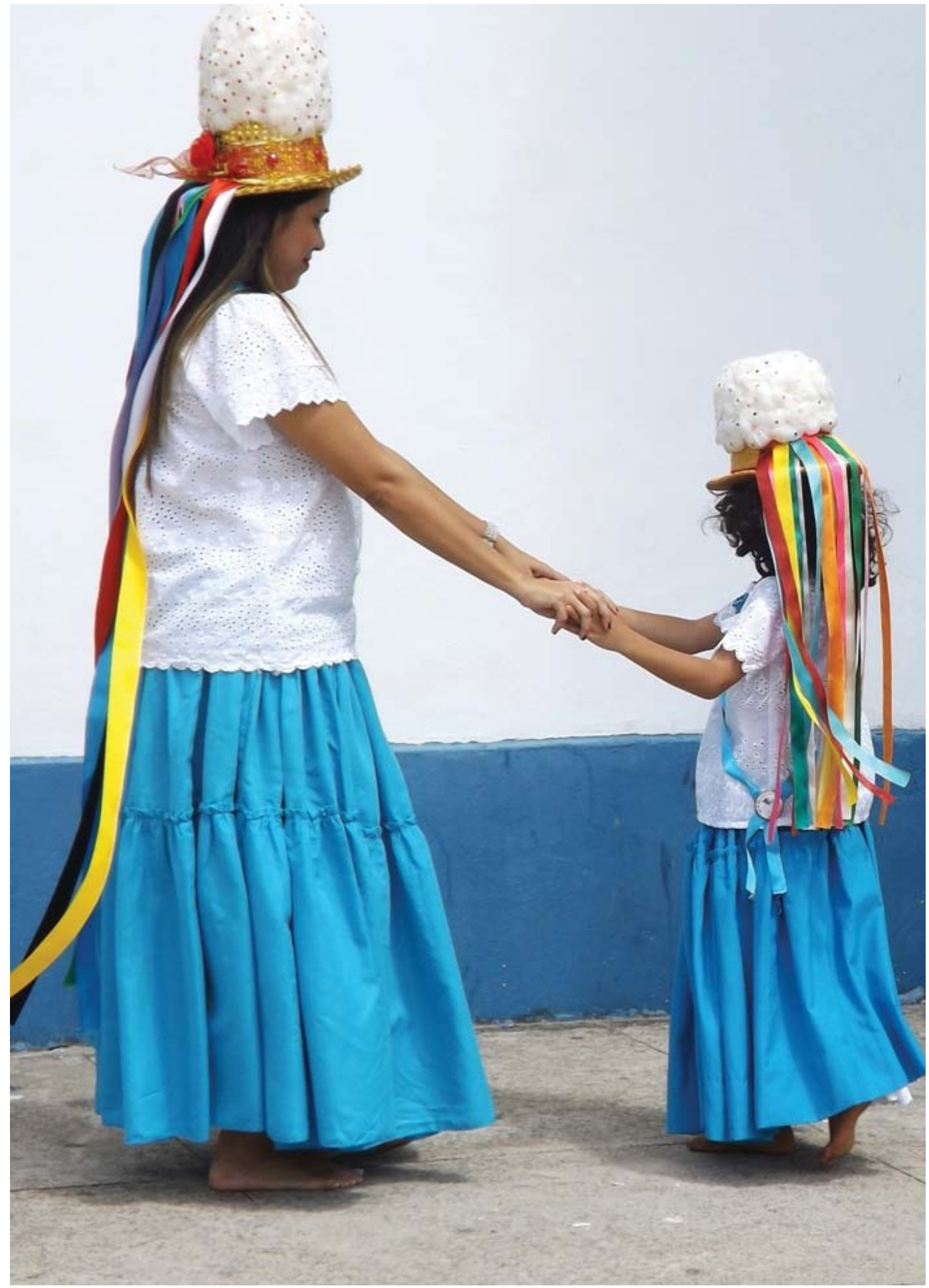

Figura 5 - Um dos meios de perpetuação da manifestação é o repasse geracional. E comum observar mães e filhas ou avós e netas participando juntas do ritual. 
Corrêa, E. P.

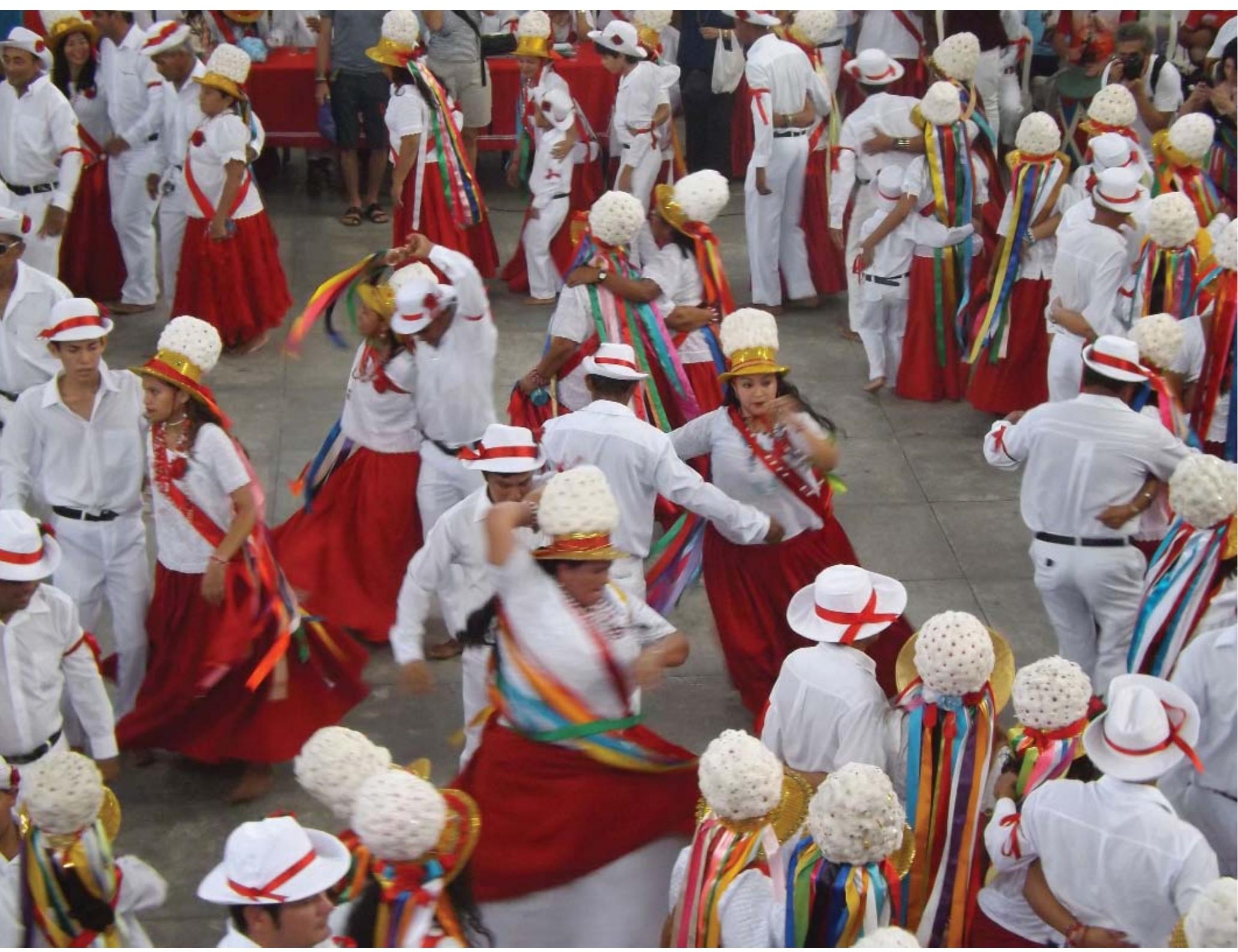

Figura 6 - Além do barracão marujas e marujos também se encontram no dia 26 de dezembro, com os trajes vermelhos, no Teatro Museu da Marujada para dançar a roda, o retumbão, a mazurca, a valsa e o xote, durante o período da manhã, e também a noite após a procissão. 


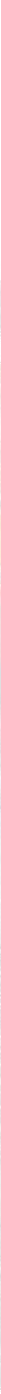

Figura 7 - O cordão das marujas, que se forma em frente à Igreja na saída da procissão de São Benedito; são elas que vão à frente da procissão. 
Corrêa, E. P.

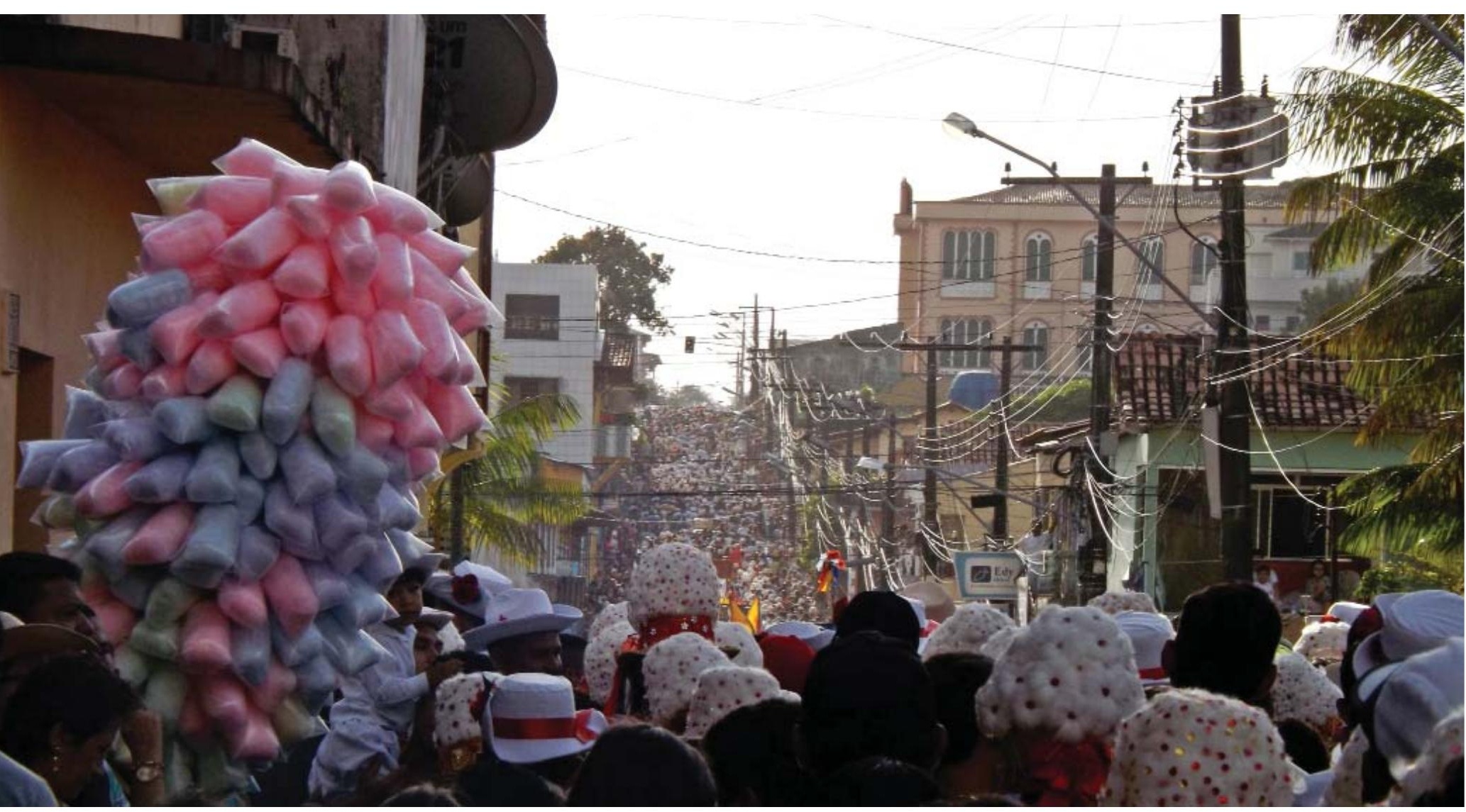

Figura 8 - A procissão de São Benedito acontece no dia 26 de dezembro, dia do 'Santo Preto', uma multidão de marujas e marujos saem nas ruas com seus trajes vermelhos e chapéus, sendo a cor branca dos chapéus um destaque durante a procissão. 


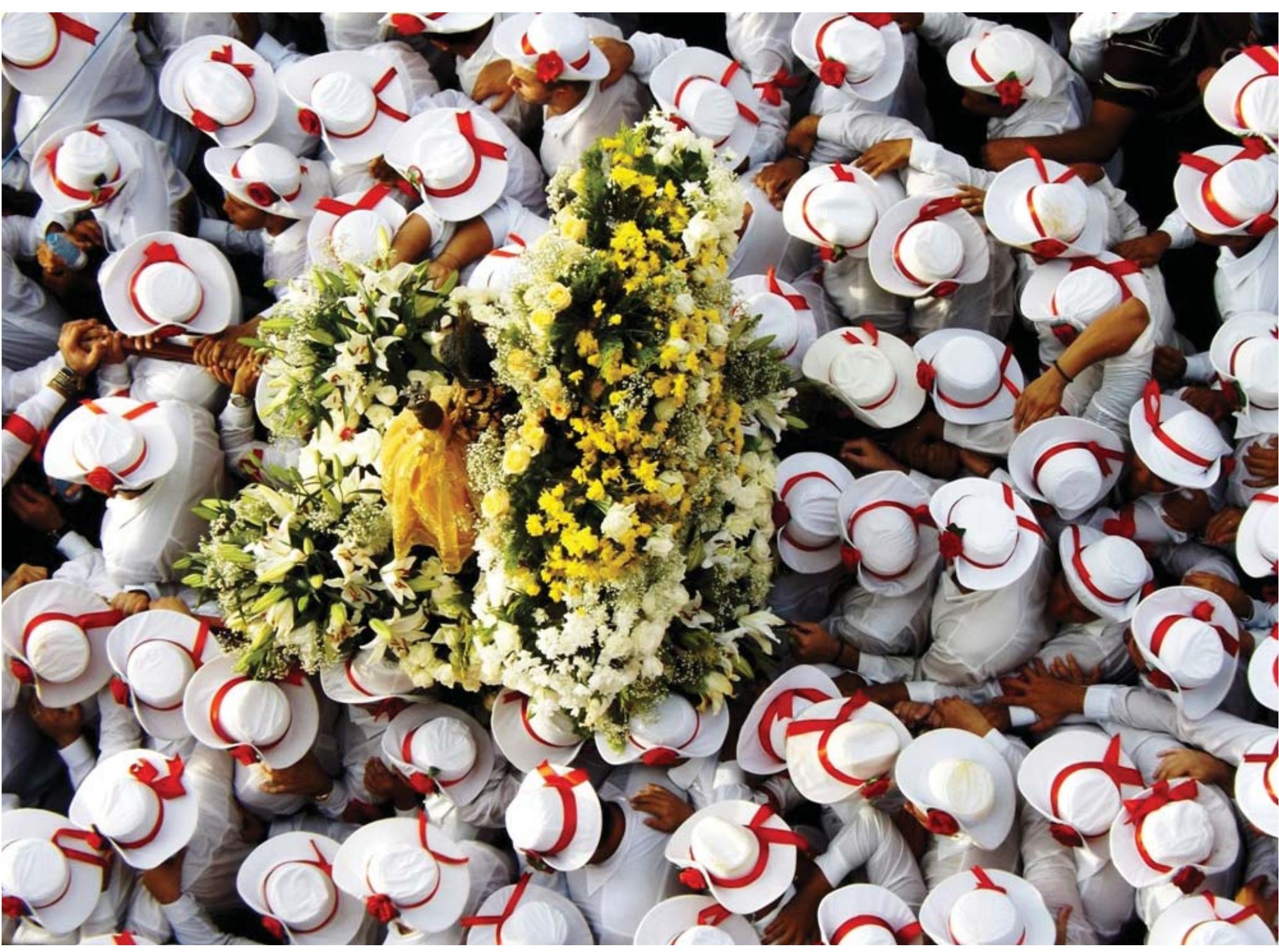

Figura 9-O Andor do Santo é carregado somente por marujos, mesmo que a participação das mulheres seja em maior número, o andor é um espaço de privilégio masculino. 
Corrêa, E. P.

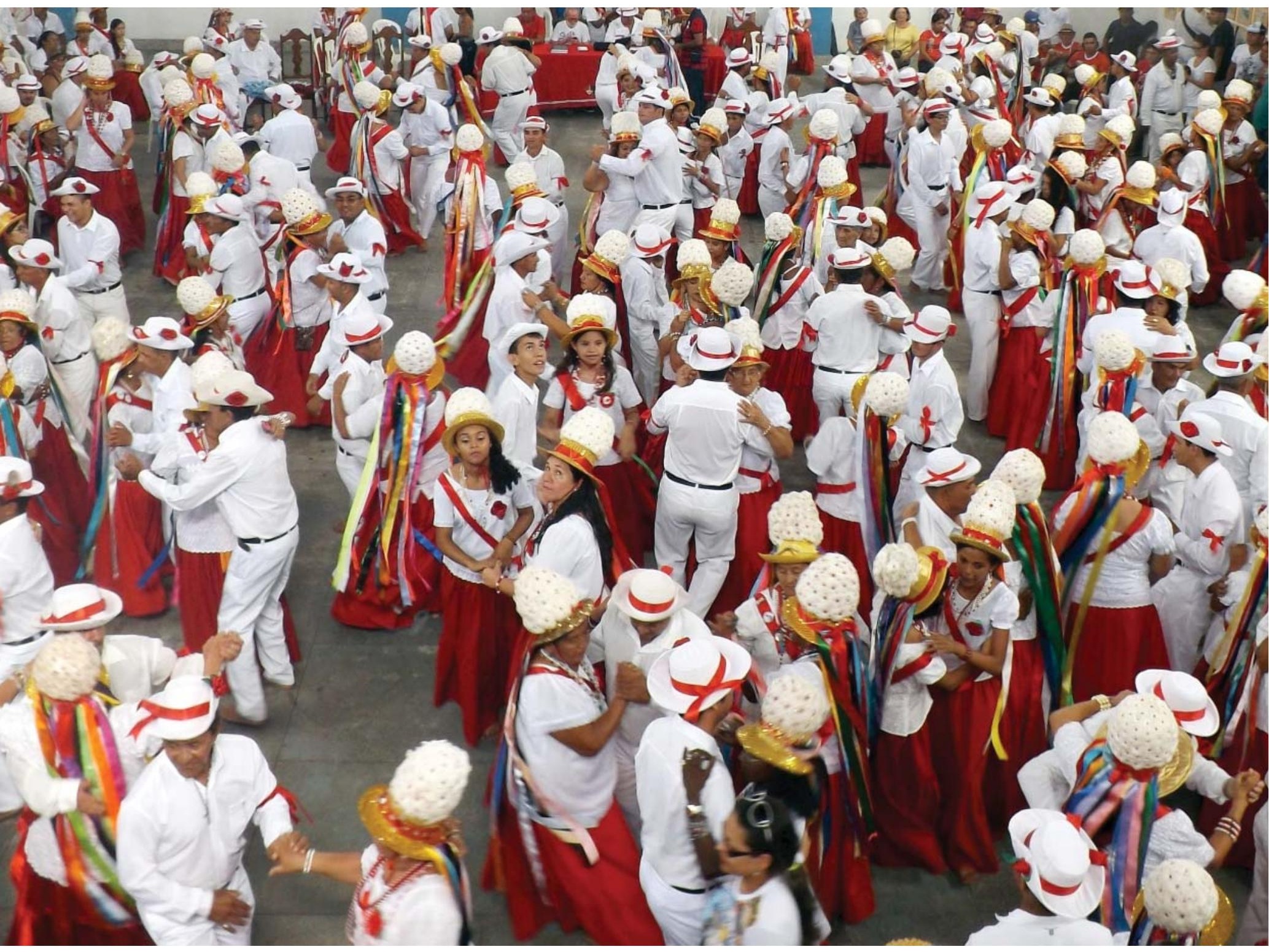

Figura 10 - Marujas e marujos dançam no Museu da Marujada, após a procissão, despedindo-se da festa, que será encerrada com o abraço simbólico de marujas e marujos na Igreja de São Benedito. 